\title{
Costs of asthma according to the degree of severity
}

\author{
J. Serra-Batlles*, V. Plaza*, E. Morejón+, A. Comella*, J. Brugués*
}

Costs of asthma according to the degree of severity. J. Serra-Batlles, V. Plaza, E. Morejón, A. Comella, J. Brugués. @ERS Journals Ltd 1998.

ABSTRACT: An increase in asthma-related morbidity and mortality has been reported recently, resulting in a substantial increase in the economic impact of this condition. Little information is available relating to the costs of asthma depending on the degree of severity of the disease.

Total, direct and indirect costs generated by asthma patients who sought medical care for asthma control over a one-year period in a northern area of Spain were determined. Data were obtained from the patients themselves and severity of illness was classified into mild, moderate and severe according to the International Consensus Report on Diagnosis and Treatment of Asthma, 1992.

The average total annual asthma-derived cost was estimated at US\$2,879 per patient, with averages of US\$1,336 in mildly asthmatic patients, US\$2,407 in moderate asthma and US\$6,393 in severe asthma. At all levels of severity, indirect costs were twice as high as direct costs, and at the same degree of severity, direct costs due to medication and hospitalization were higher among females than males. A minority of severe asthmatics incurred some $41 \%$ of the total costs.

The cost of asthma was surprisingly high and varied substantially depending on the degree of severity of the disease. Further knowledge of the costs of asthma across various levels of severity will contribute to a better characterization of optimal intervention strategies for asthma care.

Eur Respir J 1998; 12: 1322-1326.
*Service of Pneumology, Hospital General de Vic, Barcelona, Spain. ${ }^{+}$Medical Dept, GlaxoWellcome, S.A., Madrid, Spain.

Correspondence: J. Serra-Batlles

Service of Pneumology

Hospital General de Vic

Francesc Pla "El Vigata" 1

E-08500 Vic, Barcelona

Spain

Fax: 34938850308

Keywords: Asthma

cost of illness

degree of severity

economics

Received: February 111998

Accepted after revision July 311998
Asthma is a common illness estimated to affect $>5 \%$ of the adult population $[1,2]$ with a high economic burden on healthcare resources in industrialized countries [3-5]. Moreover, increases in morbidity and mortality associated with this condition have been recently reported [6-8]. In Spain, the prevalence of adult asthma varies between 1 and $4.7 \%$ depending on the geographical region studied [9]. For various reasons, the costs associated with asthma are increasing rapidly, representing $1 \%$ of total healthcare costs in the USA [3]. There is a large variation in the total average annual costs per affected person by country (e.g., US\$640 in the USA and US\$1,315 in Sweden) owing to the differences among countries in the assessment of indirect costs, in the treatment of asthma, and in the healthcare systems [3, 5, 7, 8, 10-14]. Alternatively, the economic impact of asthma care would be expected to vary according to the severity of illness. However, there is little information relating to the costs of asthma depending on the degree of severity of the disease. One major issue in defining costs by severity is that the largest proportion of persons with asthma, i.e. those with mild illness, reflects a low annual average cost. Further knowledge of how the cost of asthma varies with severity of disease would help to define the cost-effectiveness of interventions for individuals with mild, moderate and severe clinical asthma [15].

The aim of this study was to determine the total costs of asthma depending on the severity of disease, which was classified into mild, moderate and severe according to the
International Consensus Report on Diagnosis and Treatment of Asthma, 1992 [16].

\section{Materials and methods}

This cross-sectional study was carried out in Osona county, a semirural area in the province of Barcelona, Spain with a stable (over the past 10 yrs) population of 110,000 inhabitants. Healthcare is provided by nine primary healthcare centres and a general hospital (Hospital General de Vic) with specialists in pneumology, where the study was performed.

Between April 1994 and May 1995, asthma patients visiting either the primary healthcare centres or the general hospital for asthma symptoms or for routine control of the disease were eligible to take part in the study. Inclusion criteria were as follows: age Š 14 yrs and symptomatic disease during the previous year and voluntary participation in the study. Each patient satisfied the American Thoracic Society (ATS) definition of asthma, with symptoms of episodic wheezing, cough and shortness of breath responding to bronchodilators, and reversible airflow obstruction documented on at least one previous pulmonary function study [17]. Reversibility was defined as a $>15 \%$ increase in the forced expiratory volume in one second (FEV1) following inhalation of salbutamol [18]. In doubtful cases, a positive challenge test with methacholine was 
required [19]. Patients with concurrent chronic obstructive pulmonary disease (COPD) indistinguishable from asthma were excluded, as were patients with unstable asthma, defined as those who required changes in asthma treatment over the past 4 weeks and/or medical care due to an acute exacerbation of symptoms.

All patients were interviewed by the same researcher at the general hospital, where inclusion criteria were verified, and demographic, clinical and morbidity data were collected. Asthma-related morbidity referred to the previous year included frequency of exacerbations or asthma attacks, number of visits to the family physician, number of diagnostic procedures, number of visits to the specialist, number of hospitalizations and length of hospital stay, number of visits to an emergency service, medication used for asthma treatment during the past year, and work incapacity or absenteeism. Forced spirometry was carried out using a Sibelmed Datospir-92 (Barcelona, Spain). The following parameters were determined: $\mathrm{FEV} 1$, forced vital capacity (FVC), FEV1/FVC ratio and bronchodilator test after inhalation of salbutamol [18]. The severity of asthma was classified according to the International Consensus Report on Diagnosis and Treatment for Asthma, 1992 [16].

Total costs of asthma for the previous 12 months were analysed using a specific questionnaire designed for the study (available from the author on request). Data on expenditure for asthma were obtained directly from the patients and then checked with the medical record. Direct costs of asthma were those associated with medical care in either the prevention or the treatment of asthma. The financial department of the hospital provided the price for each expenditure that agreed with the governmental Catalan Health Service. Expenditures were calculated in US\$ (exchange rate at the time of the study, 128 Spanish pesetas per dollar) and were as follows: first visit to the specialist US\$69, subsequent visits US\$35, visit to the general practitioner (GP) (average from salary and number of patients attended) US\$3, visit to an emergency service US $\$ 86$, each day of hospitalization US\$173, radiograph US\$12, spirometry $\$ 13$, standard blood tests US $\$ 3$, serum immunoglobulin (IG) US\$8, radioallergosorbent (RAST) test US\$98, and skin prick-test US\$69. Medication expenditure was calculated according to the official registered price [20]. Indirect costs of asthma include comorbidity, costs associated with the loss of productive work by the patient, premature retirement or premature deaths. Working days lost were calculated by multiplying the number of days lost by the daily cost (based on a mean interprofessional salary of US\$1,406 per month) that represented US\$47 per working day lost [21]. Costs of temporal or permanent job invalidity were calculated by invalidity pensions. The base year for all cost calculations was 1995 .
Direct and indirect costs of asthma were analysed for the whole study population, for the subgroups of patients with mild, moderate and severe asthma, and by sex.

\section{Statistical analysis}

The Statistical Analysis Systems software package (version 6.08) (SAS Institute, Cary, NC, USA) was used for the analysis of data. Mean values of qualitative variables for each group were compared by one-way analysis of variance (ANOVA). In case of statistically significant differences, the Mann-Whitney U-test was used for specific comparisons. Categorical variables were compared by means of the Chi-squared test. A p-value $<0.05$ was considered significant.

\section{Results}

Of a total of 385 asthma patients enrolled in the study, 52 were excluded for various reasons. The study sample consisted of 333 patients, 119 males (36\%) and 214 females (64\%), with a mean age of 42 yrs (range 14-82 yrs). According to the severity of asthma, 140 (42\%) patients had mild asthma, 116 (35\%) moderate asthma, and 77 (23\%) severe asthma. The distribution of patients by sex in each of the subsets of mild, moderate and severe asthma was similar.

The average total annual asthma-derived cost was estimated at US $\$ 2,879$ per patient, US\$885 (30.8\%) of which were direct costs and US\$1,993 $(69.2 \%)$ indirect costs. The distribution of direct and indirect costs according to severity of asthma is shown in table 1 . In the three groups, indirect costs of asthma were higher than direct costs and were statistically significantly higher in the subgroup of patients with severe asthma. Patients with mild asthma showed high average total annual costs (US\$1,336). Expenditure for patients with moderate asthma was almost twice that for mild asthma and that for severe asthma was twice that for moderate asthma. There were statistically significant differences between the average total annual costs for mild asthma and for with the other two groups.

Annual asthma-derived direct costs were a mean $( \pm S D)$ of US $\$ 885 \pm 813$ per patient. The distribution of direct costs depending on the severity of asthma is shown in table 2 . The total cost of medicines was US\$133,294 with an average of US $\$ 400 \pm$ SD per patient. Medicines account-ed for $45 \%$ of direct costs and $19 \%$ of total asthma-related costs. Expenditures on medicines represented $19 \%$ of total costs for patients with mild asthma, $20 \%$ for patients with moderate asthma and $9 \%$ for patients with severe asthma. The total cost of admission to the hospital was US\$ 96,042, with an average of US\$289 per patient. The cost of hospi-

Table 1. - Total annual costs of asthma in US\$.patient ${ }^{-1}$ and by severity of illness

\begin{tabular}{lccr}
\hline Degree of severity & Direct costs & $\begin{array}{c}\text { Indirect costs } \\
\text { (out of work+invalidity) }\end{array}$ & Total \\
\hline Mild $(\mathrm{n}=140)$ & 74,532 & $77,484+35,000(\mathrm{n}=4)$ & $187,016^{*}$ \\
Moderate $(\mathrm{n}=116)$ & 121,197 & $104,813+52,500(\mathrm{n}=6)$ & 279,270 \\
Severe $(\mathrm{n}=77)$ & 98,292 & $219,000+175,000^{*}(\mathrm{n}=20)$ & 492,292 \\
Total $(\mathrm{n}=333)$ & 294,781 & $401,297+262,500$ & 958,578 \\
Per patient & 885 & $1205+788$ & 6393 \\
\hline
\end{tabular}

*: $\mathrm{p}<0.05$. 
Table 2. - Annual direct costs of asthma in US\$.patient-1 and by severity of illness

\begin{tabular}{lcccc}
\hline Costs related to & $\begin{array}{c}\text { Mild } \\
(\mathrm{n}=140)\end{array}$ & $\begin{array}{c}\text { Moderate } \\
(\mathrm{n}=116)\end{array}$ & $\begin{array}{c}\text { Severe } \\
(\mathrm{n}=77)\end{array}$ & $\begin{array}{c}\text { Total } \\
(\mathrm{n}=333)\end{array}$ \\
\hline $\begin{array}{l}\text { Drugs } \\
\text { Visits to: }\end{array}$ & $253 \pm 276^{*}$ & $473 \pm 310$ & $559 \pm 340$ & $400 \pm 329$ \\
General practitioner & $18 \pm 23$ & $26 \pm 27$ & $39 \pm 34$ & $26 \pm 29$ \\
Specialist & $60 \pm 56$ & $81 \pm 142$ & $82 \pm 119$ & $72 \pm 107$ \\
Hospitalization & $119 \pm 501^{*}$ & $366 \pm 927$ & $480 \pm 1247$ & $289 \pm 884$ \\
Emergency service & $35 \pm 75$ & $58 \pm 95$ & $75 \pm 119$ & $52 \pm 95$ \\
Diagnostic tests & $48 \pm 74$ & $46 \pm 74$ & $42 \pm 77$ & $46 \pm 76$ \\
Total & $533 \pm 833^{*}$ & $1050 \pm 1323$ & $1277 \pm 1703$ & $885 \pm 813$ \\
\hline
\end{tabular}

Data are mean \pm sD. $*: \mathrm{p}<0.05$.

talization accounted for $33 \%$ of direct costs and $14 \%$ of total asthma-derived costs, as well as $9 \%$ of total cost in mild asthma, $15 \%$ in moderate asthma and $8 \%$ in severe asthma. The cost of visits to physicians, either GPs or specialists, averaged US\$32,704, which represented US\$72 for a visit to a specialist and US\$26 for a visit to a GP per patient. Total direct costs and expenditures in medicines and hospitalization were significantly lower in the group of patients with mild asthma than in the other two groups (moderate and severe).

Annual asthma-derived indirect costs averaged US\$ 1,993 per patient. Patients with mild asthma showed statistically significant differences in annual averaged indirect costs (US\$803) compared with patients with moderate asthma (US\$1,356) and severe asthma (US\$5,117). Thirtytwo patients of working age (six mild asthma, six moderate asthma, 20 severe asthma) had temporal or permanent invalidity, with a total average costs of US\$262,500 and an average of US $\$ 8,750$ per patient. The total number of working days lost over a one-year period was 8,561 (table 3 ), which accounted for US\$401,297 (US\$77,484 in mild asthma, US\$104,813 in moderate asthma and US $\$ 219,000$ in severe asthma).

As shown in table 4, total direct costs, expenditures for medicines and costs of hospitalization were significantly higher in females than in males, independently of the severity of disease.

According to a sensitivity analysis considering the economic costs of 1998 and assuming that patients will be given the same medication as in 1994-1995 and the currency exchange rate will be the same as at the time of the study, the conclusions obtained will not change significantly. There will be a general increase in asthma costs of $3 \%$, with proportional increases for each group of severity.

\section{Discussion}

This study is one of the few investigations to analyse the total costs of asthma according to the severity of illness and provides evidence of differences in the economic

Table 3. - Working days lost according to severity of asthma

\begin{tabular}{lcccr}
\hline Days lost, number & $\begin{array}{c}\text { Mild } \\
(\mathrm{n}=140)\end{array}$ & $\begin{array}{c}\text { Moderate } \\
(\mathrm{n}=116)\end{array}$ & $\begin{array}{c}\text { Severe } \\
(\mathrm{n}=77)\end{array}$ & $\begin{array}{c}\text { Total } \\
\text { days }\end{array}$ \\
\hline None & $108(77 \%)$ & $83(72 \%)$ & $52(73 \%)$ & \\
$1-5$ & 7 & 4 & 1 & 29 \\
$6-10$ & 9 & 4 & 2 & 114 \\
$11-15$ & 3 & 6 & 0 & 134 \\
$>16$ & 13 & 19 & 22 & 8284 \\
Total day & 1653 & 2236 & 4672 & 8561 \\
\hline
\end{tabular}

impact of asthma care in relation to the severity of illness. It should be noted that a small number of asthmatic patients $(14 \%)$ accounted for a large part of the total average annual costs (47\%). Moreover, indirect costs of some patients with severe asthma, such as those with job invalidity and continuous working days lost, averaged US\$393,409. $\mathrm{yr}^{-1}$ and accounted for $41 \%$ of total asthma-derived costs. The costs of asthma for patients with moderate disease were almost twice as high as for mildly asthmatic patients, whereas the costs of asthma for patients in the severe group were almost three-times higher than for those with moderate asthma and five-times higher than for those with mild illness. Therefore, there is a relationship between severity of disease and increases in both the direct and indirect costs of asthma. It is likely that this phenomenon occurs in many countries. A study carried out in Canada [10] showed that $10 \%$ of asthmatics incurred some $50 \%$ of total costs of asthma.

Analysis of the direct costs of asthma also showed a relationship with severity of illness. Asthma-derived costs in patients with mild illness were significantly lower (50\%) than in patients with moderate asthma, owing to expenditure on medicines and hospital admission. There were no differences between the subgroups of moderate and severe asthma. Drug costs make up the largest proportion of direct costs of asthma. In the majority of studies, drug costs make up 30-40\% of the total direct costs of asthma, and represent the major cost for mild and moderate asthmatic patients [4]. In the present study, expenditure on medicines represented $45 \%$ of the total direct costs of asthma and, according to the severity of illness, $47 \%$ in mild asthma, $45 \%$ in moderate asthma and $44 \%$ in severe asthma. Drug costs in the mildly asthmatic patient were low and $50 \%$ lower than in moderate and severe asthmatic patients.

Table 4. - Annual total costs of asthma in US\$.patient-1 by sex

\begin{tabular}{lcc}
\hline Costs related to & $\begin{array}{c}\text { Male } \\
(\mathrm{n}=119)\end{array}$ & $\begin{array}{c}\text { Female } \\
(\mathrm{n}=214)\end{array}$ \\
\hline Drugs & $351 \pm 309$ & $429 \pm 338$ \\
Visits to: & $21 \pm 24$ & $29 \pm 31$ \\
General practitioner & $66 \pm 67$ & $76 \pm 124$ \\
Specialist & $144 \pm 566$ & $369 \pm 1012^{*}$ \\
Hospitalization & $41 \pm 81$ & $59 \pm 101$ \\
Emergency service & $43 \pm 69$ & $47 \pm 81$ \\
Diagnostic tests & $666 \pm 943$ & $1009 \pm 1445^{*}$ \\
Total direct costs & $1163 \pm 3304$ & $1606 \pm 3449$ \\
Total indirect cost & $1829 \pm 4035$ & $2615 \pm 4654$ \\
Total costs of asthma & & \\
Data are mean \pm sD. $*: \mathrm{p}<0.05$. & &
\end{tabular}


Differences in drug costs between patients with moderate and severe asthma were scarce, probably because oral corticosteroids, the treatment regimen that mostly differentiates moderate from severe asthmatics, are low-cost products. Although the price of medicines is somewhat lower than in other countries that are similar to Spain, in the year in which the study was carried out salmeterol was the only long-acting $\beta_{2}$-agonist available on the market, the price of which was much higher than that of other bronchodilators in use until 1992.

Total hospital costs represented 22, 35 and $38 \%$ of the direct costs of asthma for patients with mild, moderate and severe illness, respectively, and 33\% for the whole study population. This figure is similar to that reported in studies carried out in Sweden [14] and Canada [10] in 1990. In most countries, total hospital costs are typically around $20-25 \%$ of the direct costs of asthma [4]. In the present study, visits to physicians accounted for $11 \%$ of direct costs, which is much lower than figures of $30 \%$ found in France [11], 20\% in the UK [13], 40\% in Sweden [14], $31 \%$ in Australia [22] and $17 \%$ in asthmatic adults in the USA [3]. It should be taken into account that medical fees in Spain are the lowest in Europe. Statistically significant differences between groups depending on the severity of disease were not found.

Indirect costs also varied according to severity of disease. Working days lost averaged $60 \%$ of the indirect costs of asthma in the whole study population, representing $70 \%$ in the group of mild asthma, $67 \%$ in moderate asth-ma and $56 \%$ in severe asthma. Costs of invalidity pensions showed an inverse relationship: the greater the severity of asthma, the higher the proportion of costs of invalidity in respect to the total indirect costs of asthma.

In the present study, direct costs were greater than indirect costs. Of the nine studies analysed by BARNES et al. [4], direct costs were greater than indirect costs in four $[3,10$, $11,23]$, similar in two $[12,22]$ and lower in three $[5,13$, 14], two of which were carried out in Sweden and one in the UK. In a study of direct and indirect costs of asth-ma in Canada in 1990, KRAHN et al. [24] concluded that the annual costs of treating asthma were comparable to the individual costs of infectious diseases, haematological diseases, congenital defects, perinatal illnesses, homecare and ambulance services. The single largest component of direct costs was the cost of drugs and the largest component of indirect costs was illness-related disability [24]. In a national estimate of the economic cost of asthma based on the 1987 National Medical Expenditure Survey, Sмттн et al. [25] found that hospitalization accounted for more than half of all expenditure and that $>80 \%$ of resources were used by $20 \%$ of the population (defined as "high-cost patients"). The cost of asthma therapy in Germany was analysed by Graf von der Schulenburg et al. [26], who showed a positive correlation between average total costs and degree of severity. Therefore, preventive medical treatment of asthma that slows the progression of the illness would have a positive effect on the total expenditure per patient. WEINSTEIN et al. [27] reported that short-term inpatient rehabilitation for children with severe asthma was significantly associated with a reduction in the estimated total medical charges over a four-year follow-up period.

When costs of asthma were analysed by sex, drug costs and hospital costs and, in consequence, the total direct costs of asthma were significantly higher in females than in males. However, differences in indirect costs were not observed. This may be interpreted as females confronted with a chronic illness being more concerned than males, thus seeking medical care more often and having more medicines prescribed.

In summary, the costs of asthma varied substantially depending on the degree of severity of the disease. The progressive increase in the severity of illness causes a considerable increase in the total costs of asthma. A minority of some asthmatics incurred $41 \%$ of the total costs. Further knowledge of the costs of asthma across various levels of severity will contribute to a better characterization of optimal intervention strategies for asthma care [28]. In addition, there is need for agreement for the use of standard outcome measures to ensure the comparability of data from different cost-effectiveness analyses of asthma.

Acknowledgements: The authors thank J.M. Antó, Dept of Epidemiology and Public Health, Institut Municipal d'Investigació Mèdica (IMIM), Barcelona, for his technical advice, A. Pedromingo, for statistical support, and $\mathrm{M}$. Pulido, for editing the manuscript and editorial assistance.

\section{References}

1. Woolcock AJ. Worldwide differences in asthma prevalence and mortality. Why is asthma mortality so low in the USA? Chest 1986; 90: Suppl, 40-45.

2. Evans R, Mullaly DI, Wilson RW. National trends in the morbidity and mortality of asthma in the US. Chest 1987 ; 91: Suppl. 6, 65-74.

3. Weiss KB, Gergen PJ, Hodgson TA. An economic evaluation of asthma in the United States. N Engl J Med 1992; 326: 862-866.

4. Barnes PJ, Jonsson B, Klim JB. The cost of asthma. Eur Respir J 1996; 9: 636-642.

5. Thompson S. On the social cost of asthma. Eur J Respir Dis 1984; 136: Suppl, 185-191.

6. Burr ML, Butland BK, King S, Vaughan Williams E. Changes in asthma prevalence: two surveys 15 years apart. Arch Dis Child 1989; 64: 1452-1456.

7. Alderson M. Trends in morbidity and mortality from asthma. Population Trends 1987; 49: 18-23.

8. Anderson HR. Is the prevalence of asthma changing? Arch Dis Child 1989; 64: 172-175.

9. Grupo Espanol del Estudio Europeo del Asma. Estudio Europeo del Asma. Prevalencia de hiperreactividad bronquial y asma en adultos jóvenes de cinco áreas espanolas. Med Clin (Barc) 1996; 106: 761-767.

10. Boston Consulting Group. The cost of adult asthma in Canada. Princeton, NJ, Communications Media for Education, 1993.

11. Boston Consulting Group/CRESGE. Asthme: mieux connaitre pour mieux traiter. Paris, Glaxo, 1992.

12. Action Asthma. The occurrence and cost of asthma. West Sussex, Cambridge Medical Publications, 1990.

13. Teeling-Smith G. Asthma. London, Office of Health Economics, 1990.

14. Jacobson L, Lindgren B. Asthma. De samhäll sekonomiska Kostnaderna, Studier y hälsorkonomi 8. Lund, Lund Universistet, 1995.

15. Weiss KB. The health economics of treating mild asthma. Eur Respir Rev 1996; 6: 45-49.

16. International Consensus Report on Diagnosis and Treatment of Asthma. Clin Exp Allergy 1992; 1: 1-72.

17. American Thoracic Society. Standards for the diagnosis and care of patients with chronic obstructive pulmonary 
disease (COPD) and asthma. Am Rev Respir Dis 1987; 136: 225-244.

18. Grupo Trabajo de la SEPAR. Normativa para la espirometría forzada. Recomendaciones SEPAR 2. Barcelona, Ediciones Doyma, 1985.

19. Grupo Trabajo de la SEPAR. Normativa para los tests de provocación bronquial inespecifica. Recomendaciones SEPAR 4. Barcelona, Ediciones Doyma, 1987.

20. Medicom SA. Vademecum Internacional. Madrid, Medi Medic, 1995.

21. Instituto Nacional de Estadística (INE). Boletín mensual de estadística, Madrid, 1995; 37 (January): 147.

22. National Asthma Campaign. Report on the cost of asthma in Australia, 1993.

23. Mellis CM, Peat JK, Bauman AE, Woolcock AJ. The cost of asthma in New South Wales. Med J Aust 1991; 155: $522-528$.
24. Krahn MD, Berka C, Langlois P, Detsy AS. Direct and indirect costs of asthma in Canada, 1990. Can Med Assoc $J$ 1996; 154: 821-831.

25. Smith DH, Malone DC, Lawson KA, Okamoto LJ, Battista C, Saunders WB. A national estimate of the economic costs of asthma. Am J Respir Crit Care Med 1997; 156: 787-793.

26. Graf von der Schulenburg JM, Greiner W, Molitor S, Kielhorn A. Cost of asthma therapy in relation to severity. An empirical study. Med Klin 1996; 91: 670-676.

27. Weinstein AG, McKee L, Stapleford J, Faust D. An economic evaluation of short-term inpatient rehabilitation for children with severe asthma. J Allergy Clin Immunol 1996; 98: 264-273.

28. Goldstein RS, Gort EH, Guyatt GH, Feeny D. Economic analysis of respiratory rehabilitation. Chest 1997; 112: 370-379. 